Ensino, Saúde e Ambiente - V10 (1), pp. 104-122, Abril. 2017

\title{
APLICAÇÃO DO PLANEJAMENTO ESTRATÉGICO SITUACIONAL NO CURSO DE BACHARELADO EM PSICOLOGIA DO CENTRO UNIVERSITÁRIO LUTERANO EM PALMAS (TO)
}

\section{APPLICATION OF SITUATIONAL STRATEGIC PLANNING IN THE COURSE OF BACHELOR IN PSYCHOLOGY OF LUTHERAN UNIVERSITY CENTER OF PALMAS (TO)}

\author{
${ }^{1}$ Waldecy Rodrigues, ${ }^{2}$ Rosangela Veloso Freitas, ${ }^{3}$ Juliana Ferreira Queiroz, ${ }^{4}$ \\ Raquel Bezerra Barros \\ ${ }^{1}$ Universidade Federal do Tocantins / Programa de Pós-Graduação em Desenvolvimento Regional / \\ waldecy@terra.com.br \\ ${ }^{2}$ Instituto Federal de Ciência e Tecnologia do Estado do Tocantins / Campus de Paraíso / \\ rosangelapsi@ifto.edu.br \\ ${ }^{3}$ Instituto Federal de Ciência e Tecnologia do Estado do Tocantins / Campus de Paraíso / \\ juliana.queiroz@ifto.edu.br \\ ${ }^{4}$ Instituto Federal de Ciência e Tecnologia do Estado do Tocantins / Campus de Paraíso / \\ raquel.bb@ifto.edu.br
}

\begin{abstract}
RESUMO
O presente trabalho tem por objetivo propor e discutir práticas de melhoria do processo de ensino-aprendizagem no curso de Bacharelado em Psicologia do Centro Universitário Luterano de Palmas - TO. Trata-se de um estudo de caso, com base referencial no método de Planejamento Estratégico Situacional (PES). A primeira etapa da pesquisa buscou levantar a revisão bibliográfica sobre a criação e conceitos relacionados ao PES, possibilitando o delineamento da metodologia a ser utilizada na pesquisa. Na sequência dos momentos do PES o trabalho buscou identificar os problemas, os nós críticos e os diferentes atores e seus recursos. Foram ainda elaboradas estratégias de melhorias, finalizando-se com a proposição de ações estratégicas relacionadas ao êxito escolar dos discentes deste curso. As conclusões defendem que o método PES contribuiu de maneira positiva para a melhoria do processo de planejamento pedagógico do curso de Psicologia.
\end{abstract}

Palavras-chave: Planejamento estratégico situacional; ensino superior; psicologia.

\begin{abstract}
The present papper proposes and discusses practices of improvement of the teachinglearning process in the course of Bachelor of Psychology of the Lutheran University Center of Palmas - TO. This is a case study, based on the Strategic Situational Planning (SEP) method. The first stage of the research sought to raise the bibliographic review on the creation and concepts related to SEP, allowing the design of the methodology to be used in the research. Following the moments of the SEP the work sought to identify the problems, the critical nodes and the different actors and their resources. Strategies of improvement were also elaborated, ending with the proposal of strategic actions related to the scholastic success of the students of this course. The conclusions defend that the SEP method contributed positively to the improvement of the pedagogical planning process of the Psychology course.
\end{abstract}

Keywords: Situational strategic planning; higher education; psychology. 


\section{INTRODUÇÃO}

Existe uma nítida dificuldade de uma linha de educadores que rejeitam a ideia do planejamento estratégico em desenvolver ações para a melhoria do processo de ensinoaprendizagem, pelo argumento de trazer elementos da gestão empresarial para dentro das unidades de ensino. A preocupação tem uma certa razão, pois o próprio Carlos Matus faz severas críticas ao planejamento tradicional, por não considerar o princípio dialógico, e ser construído de forma rígida e por vezes de cima para baixo.

Segundo Matus (1996), o governo latino-americano, de modo geral, é caracterizado pela "mediocridade ultra estável" resultante de regras centralizadas e de baixa responsabilidade incompatíveis com a diversidade de interesses que existem nas sociedades atuais. Em sua argumentação, Matus expõe a fragilidade do planejamento tradicional, uma vez que, não considera a atuação dos outros atores no jogo social, além disso, seria pouco flexível às mudanças o que o tornaria, inevitavelmente, defasado e pouco preparado para o futuro. Para ele o raciocínio determinista, encontrado no planejamento tradicional é "demasiado simples e perigoso, mas que, por ser simples, está muito firmemente implantado nas cabeças que adoram a estática dos problemas bem-estruturados que têm soluções objetivas precisas" (1993, p. 23).

O Planejamento Estratégico Situacional (PES), concebido pelo economista chileno Carlos Matus é ao mesmo tempo uma teoria e um método. Parte da ideia de que o planejamento antecede as ações, um planejamento que se faça sistematicamente, metodicamente e envolvendo todos os atores envolvidos em um problema central. A princípio serviu aos dirigentes políticos e suas atuações sobre um problema público, onde se pressupõe jogos políticos, econômicos e sociais. (BIRCHAL; BERMEJO; ZAMBALDE, 2012).

O PES é uma metodologia participativa, construtivista e dialógica e é muito interessante para ser utilizada no planejamento institucional e até mesmo pedagógico. Porém, deve ser realizado em situações-problema complexas e que de fato exijam um esforço estratégico. Como um dos resultados na pesquisa de Darosi (2014), está concentrada na área de saúde e de gestão, tendo um bom espaço a ser ocupado no campo da educação.

Especificamente, no âmbito educacional foram localizados apenas três artigos no Portal Scielo fazendo referência ao uso do PES em instituição de ensino superior, sendo eles: o uso das metodologias "planejamento estratégico situacional" e "mapeamento 
cognitivo" em uma situação concreta: o caso da pró-reitoria de extensão da UFSCar ( RIEG; FILHO, 2002), o estudo de Bernardino et al (2006) que fez a seleção de algumas estratégias a serem utilizadas pelos cursos de graduação em enfermagem para despertar no aluno maior interesse na área de saúde coletiva e a análise do plano de desenvolvimento institucional das universidades federais do consórcio sul-sudeste de Minas Gerais (MIZAEL et al, 2013).

Assim, este trabalho pretende aplicar o método de Planejamento Estratégico Situacional - PES em uma Instituição de Ensino Superior, tendo como estudo de caso o curso de Bacharelado em Psicologia do Centro Universitário Luterano de Palmas CEULP/ULBRA.

\section{MATERIAL E MÉTODOS}

\section{Planejamento Estratégico Situacional (PES)}

Matus (1993) apresentou o PES - Planejamento Estratégico Situacional, como uma alternativa ao planejamento tradicional. Tem como características: o subjetivismo, em que cada indivíduo tem sua interpretação dos fatos mediante suas crenças, experiências e posição no jogo social; a elaboração de planos e propostas a partir de problemas e a incerteza sobre o futuro, como possível prever, mas impossível predizer.

De acordo com Gonçalves (2010), a crítica ao planejamento tradicional seria o pano de fundo da elaboração do PES, servindo ao mesmo tempo como sustentação e valorização do método proposto. Neste particular, o PES é apresentado como um modelo pautado na democracia e na descentralização, no qual o plano é fruto de uma criação coletiva.

Matus defende que as ações de planejamento estão inseridas em um contexto que ultrapassa o cenário e atores do presente, para ele: "planejar é tentar submeter o curso dos acontecimentos à vontade humana, não deixar que nos levem e devemos tratar de ser condutores de nosso próprio futuro, trata-se de uma reflexão pela qual o administrador público não pode planejar isoladamente, esta se referindo a um processo social, no qual realiza um ato de reflexão, que deve ser coletivo, ou seja, planeja quem deve atuar como indutor do projeto". (MATUS, 1993, p. 13)

A partir de sua crítica, Matus (1993) expõe seis pressupostos para o planejamento estratégico situacional: 
1. O ator que planeja não tem assegurada sua capacidade de controlar a realidade, porque isso dependerá da ação de outros atores;

2. Existe mais de uma explicação para a realidade, em função dos vários atores;

3. Vários atores sociais enfrentam-se, com objetivos conflitantes;

4. O poder é escasso e o planejamento deve sistematizar o cálculo político e centrar sua atenção na conjuntura;

5. A incerteza é predominante;

6. O governante lida com problemas no tempo, e com solução aberta à criação e ao conflito.

Neste sentido, o PES é método de alta complexidade e alta potência, apropriado para o nível diretivo de instituições de grande porte e com pessoal especializado. É uma alternativa de planejamento por problemas e trata, principalmente, dos problemas mal estruturados e complexos, para os quais não existe solução normativa ou previamente conhecida como no caso daqueles bem estruturados. Esses problemas são sempre abordados em suas múltiplas dimensões - política, econômica, social, cultural, etc. e em sua multissetorialidade, pois suas causas não se limitam ao interior de um setor ou área específicos e sua solução depende, muitas vezes, de recursos extra-setoriais e da interação dos diversos atores envolvidos na situação (ARTMANN, 1997).

Em sua concepção, Matus definiu 4 (quatro) momentos importantes para a elaboração e implementação do método PES: o momento explicativo, o normativo prescritivo, o estratégico e o tático operacional.

O momento explicativo é o equivalente ao diagnóstico no planejamento normativo. Parte-se da compreensão de que um Ator Social possui "problemas" e é a partir deles que deve explicar situacionalmente a realidade. Deve-se montar um "fluxograma" onde o (s) problema (s) selecionado (s) é (são) decomposto (s) em suas causas, descritores e consequências para o Ator Social que o está explicando, segundo seus valores, objetivos e conduta. As causas dos problemas podem ser decompostas em toda sua complexidade, constituindo elas mesmos subproblemas (DE TONI, 2008).

O momento normativo é o desenho do deve ser, nossa definição de como deve ser a realidade. Aqui o mais importante é estabelecer objetivos em função de cada problema ou grupo de problemas. Este é o momento da manifestação da intencionalidade do Ator Social, de sua vontade de mudar as coisas, atuando sobre a raiz dos seus problemas. A situação objetivo deve ser precisa em relação aos problemas e 
elementos destacados no modelo explicativo da situação inicial. Outro aspecto do momento normativo é a construção de cenários, que se constituem de exercícios para imaginar diferentes possibilidades de ação.

No momento estratégico é chegada a hora de analisar a viabilidade das operações que foram desenhadas nos momentos anteriores, essas operações podem ser conflitivas do ponto de vista político, muito exigentes do ponto de vista econômico, ou demandante de tecnologia de elevada complexidade. Nesse momento, deve-se verificar se há contradições entre os objetivos (análise de coerência), se os recursos, tecnologias e organização estão disponíveis (análise de factibilidade) e se é possível contornar os obstáculos políticos (análise de viabilidade) (PAIM, 2006). Todas essas reflexões devem ter por objetivo construir viabilidade para as propostas de solução elaboradas no momento normativo.

O momento tático-operacional é o momento da ação, onde os planos são recalculados e aprimorados conforme as circunstâncias, garantindo a continuidade do processo sem romper com os outros três momentos e a ação diária (HUERTAS, 1996). Para Matus (1996) o plano se completa na ação, nunca antes. Somente a ação muda a realidade e este agir faz parte do plano. Não é etapa posterior. Este é momento de execução do plano sob uma determinada gerencia e organização do trabalho, com prestação de contas, supervisão, acompanhamento e avaliação. É o momento de monitorar as operações e avaliar continuamente.

\section{Procedimentos empíricos}

Trata-se uma pesquisa qualitativa, exploratória e descritiva do tipo estudo de caso. Com a abordagem e aplicação do Planejamento Estratégico Situacional (PES) de Carlos Matus. A pesquisa pretende propor e discutir práticas de planejamento estratégico com base referencial no método de PES.

A pesquisa aconteceu na Coordenação do Curso de Bacharelado em Psicologia do Centro Universitário Luterano (CEULP/ULBRA), na cidade de Palmas - TO. Participaram desta pesquisa o coordenador titular do curso, o coordenador adjunto e o corpo docente em sua totalidade.

A primeira etapa da pesquisa foi centrada na revisão de literatura relacionada ao PES, buscou-se conhecer o ponto de vista de Carlos Matus como criador do método PES e as diferentes formas de abordagem do método através do levantamento de pesquisas publicadas sobre o tema. A partir desse estudo buscou-se definir a sequência 
de etapas que melhor de aplicaria ao caso em questão, levando-se sempre em consideração a preservação e sequência dos momentos apresentados por Matus.

$\mathrm{Na}$ segunda etapa buscou-se conhecer o objeto de estudo através da promoção de reuniões e debates com os atores envolvidos. Foram realizadas cinco reuniões com a participação de membros do Colegiado e objetivos, conforme descritos:

$1^{\mathrm{a}}$ Reunião, com a participação dos gestores: Apresentação de proposta para aplicação do método PES.

$2^{\mathrm{a}}$ Reunião, com a participação dos gestores e corpo docente: Debate aberto para levantamento dos pontos fortes, pontos fracos, ameaças e oportunidades para elaboração da análise SWOT e discussão sobre os principais problemas relacionados à oferta de vagas, ao processo de ensino-aprendizagem, à pesquisa e à extensão vinculados ao curso de Psicologia.

$3^{\text {a }}$ Reunião, realizada com a participação dos gestores: Apresentação da análise SWOT feita a partir da visão social e tecnológica do colegiado, apresentação do problema principal e nós críticos e investigação da percepção dos gestores sobre os problemas apresentados.

$4^{\mathrm{a}}$ Reunião, realizada com a participação dos docentes: Abordagem voltada para a perspectiva deste grupo de atores quanto a participação dos docentes na deflagração e resolução de problemas, assim como sua participação no planejamento estratégico.

$5^{\text {a }}$ Reunião, realizada com a participação dos gestores e corpo docente: Apresentação dos resultados da pesquisa e debate sobre as medidas estratégicas apresentadas e conclusões do estudo.

$\mathrm{Na}$ etapa final foi realizada a demonstração e análise dos dados e conseguinte proposição de planejamento estratégico para o curso de Psicologia. Os resultados dos momentos da aplicação do PES serão apresentados em forma de fluxograma situacional, planilhas de ações e relatos.

\section{RESULTADOS E DISCUSSÕES}

Com base na participação em reuniões e debates com os atores envolvidos levantou-se os seguintes dados:

\section{O caso em estudo: O Curso de Psicologia do CEULP / ULBRA Palmas - TO}

O Centro Universitário Luterano de Palmas (CEULP/ULBRA) é uma instituição de direito privado regida por seu próprio Estatuto, bem como pela legislação vigente. 
Trata-se de uma entidade particular e confessional, mantida pela Comunidade Evangélica Luterana São Paulo (CELSP) que iniciou suas atividades no Tocantins no ano de 1993, dedicando-se ao ensino, pesquisa e extensão em nível superior (PDI, 2011/2016).

No seu primeiro vestibular ofertou vagas nos cursos superiores de Administração, Letras e Pedagogia. Atualmente oferece 23 cursos superiores distribuídos entre Bacharelado, Licenciaturas e Tecnológicos, nas seguintes áreas de conhecimento: Social Aplicada, Exatas e da Terra, Humanas e Saúde. Além de 19 cursos de pós-graduação presenciais, 20 na modalidade à distância/EAD, Residência Multiprofissional em Saúde e Programas de Mestrado e Doutorado.

Nessa instituição o curso de Psicologia do CEULP iniciou seu funcionamento autorizado pela Portaria MEC no 311 de 21 de março de 2000. Naquele momento estava habilitado nas modalidades de Bacharelado, Formação de Psicólogo e Licenciatura. Porém, atendendo a atualização das Diretrizes Curriculares Nacionais para os cursos de graduação em Psicologia, através da Resolução CNE/CES nº 8, de 7 de maio de 2004, não se oferece mais as modalidades Bacharelado e Licenciatura, passando a Formação em Psicologia voltada para atuação, pesquisa e ensino (PPC, 2011/2016)

O curso foi reconhecido pela Portaria MEC no 55 de 11 de janeiro de 2005. É ofertado presencialmente no turno matutino, e possui como missão "Promover o desenvolvimento de profissionais da Psicologia enquanto cidadãos comprometidos com os direitos humanos e a construção de respostas às necessidades sociais e à investigação permanente da subjetividade humana" (PPC, 2011/2016).

Em consonância com as políticas institucionais presentes no PDI, o curso apresenta entre os princípios norteadores:

- A indissociabilidade entre ensino, pesquisa e extensão;

- A flexibilização dos currículos, de forma a proporcionar ao acadêmico, na maior medida possível, a autonomia na sua formação acadêmica;

- A atualização permanente do Projeto Pedagógico do Curso, considerando as discussões sobre as diretrizes curriculares, as produções científicas e as inovações tecnológicas da área e as demandas socioeconômicas da região e do país;

- Uma discussão permanente sobre a qualidade do ensino de graduação, através de diferentes fóruns, envolvendo direção/coordenadores e Conselhos de Curso; 
- $\quad \mathrm{O}$ incentivo à produção científica e didática do corpo docente; $\mathrm{e}$

- A qualificação permanente do corpo docente, em termos de titulação acadêmica e de competências didático-pedagógicas. (PPC, 2011-2016).

Sustenta-se na oferta de uma formação generalista, abrangendo, no seu currículo, diversas concepções teórico-metodológicas e as seguintes áreas clássicas e emergentes dessa ciência: Processos clínicos, de gestão, educativos e de prevenção e promoção da saúde. Se compromete em oferecer oportunidade de construção crítica do conhecimento, estimular a investigação, aproximar teoria e práxis e fomentar a troca interdisciplinar em diferentes contextos sociais e acadêmicos norteadas pela ética profissional (PPC 2011-2016)

A presente coordenação do curso informou que atualmente o colegiado conta com 17 professores, e que o curso possui nesse momento 476 estudantes. Tem ofertado anualmente 100 vagas, e já formou, desde a sua abertura 21 turmas. Tem-se estudado a possibilidade de oferta do curso noturno, o que segundo a coordenação é uma meta de curto prazo.

\section{Análise FOFA (SWOT) - Detalhamento dos problemas identificados}

Nessa pesquisa a análise FOFA ou análise SWOT foi utilizada para análise do ambiente (cenário) no primeiro momento do PES (explicativo).

Conforme Gonzalez (2009) e Goncalves et al (2010), a análise SWOT é uma ferramenta muito utilizada por empresas na busca por orientações estratégicas. As siglas SWOT (inglês) /FOFA (português) significam Strengths (forças), Weaknesses (fraquezas), Opportunities (oportunidades) e Threats (ameaças). Os pontos fortes e fracos são determinados por elementos internos, enquanto as oportunidades e ameaças são ditadas por forças externas, o que permite sistematizar todas as informações possíveis e tomar uma decisão balanceada.

O Quadro 1 demonstra a posição atual da empresa/curso frente aos fatores internos e externos do ambiente bem como suas potencialidades e limitações atuais. Foi criado a partir da primeira reunião com os atores, na qual, mediante o uso da técnica tempestade de ideias, falaram livremente sobre o momento situacional. 


\section{Quadro 1 - Análise FOFA/ Curso Psicologia CEULP/ULBRA.}

\begin{tabular}{|c|c|c|}
\hline & Forças & Fraquezas \\
\hline 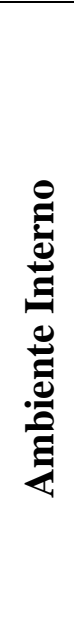 & $\begin{array}{l}\text { Qualificação dos docentes; } \\
\text { Infraestrutura (biblioteca, espaços } \\
\text { físicos, equipamentos, } \\
\text { laboratórios); } \\
\text { Gestão participativa; } \\
\text { Projetos de extensão; } \\
\text { Flexibilidade do curso (grade } \\
\text { aberta); } \\
\text { Clínica escola (SEPSI); } \\
\text { Atendimento ao aluno } \\
\text { (Aconselhamento Curricular); } \\
\text { Nota do curso nos avaliadores } \\
\text { externos (ENADE;) }\end{array}$ & $\begin{array}{l}\text { Valor da mensalidade } \\
\text { Horário do curso (diurno) } \\
\text { Baixa atuação em Pesquisa } \\
\text { Comportamento do aluno frente às } \\
\text { demandas acadêmicas. (Inatividade } \\
\text { - excesso de atividade) } \\
\text { Monitoria } \\
\text { Acompanhamento do egresso. } \\
\text { Falta de uniformidade na condução } \\
\text { do trabalho docente. }\end{array}$ \\
\hline & Oportunidades & Ameaças \\
\hline 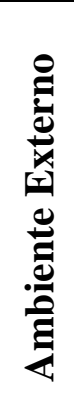 & $\begin{array}{l}\text { Campos de Estágios } \\
\text { Financiamentos estudantis } \\
\text { Acesso facilitado do aluno à } \\
\text { localidade do campus (vias } \\
\text { pavimentadas e transporte público } \\
\text { urbano) }\end{array}$ & $\begin{array}{l}\text { Mercado de trabalho saturado } \\
\text { Curso de Psicologia UFT } \\
\text { Restrições orçamentárias para } \\
\text { financiamentos estudantis } \\
\text { Negativa do Curso noturno }\end{array}$ \\
\hline
\end{tabular}

Fonte: Resultados da Pesquisa

\section{Identificação e descrição do Problema}

A partir das fraquezas expostas na Análise FOFA, e da síntese da visão social dos atores envolvidos, ainda no momento explicativo foi selecionado o seguinte problema central: Comportamento inadequado do aluno frente às demandas acadêmicas.

Os atores declarantes, nesse momento composto por coordenadores (titular e adjunto) e do corpo docente, identificaram como causas do problema: ausência de hábito de leitura continuada; uso de ferramentas de pesquisa superficiais e insuficientes; paternalismo de parte do corpo docente; método avaliativo inapropriado; errônea relação de consumo com o papel educador da instituição; carga horária docente elevada; atenuação dos problemas por motivos diplomáticos na relação instituição - aluno; falta de clareza sobre a profissão de Psicólogo. 
Diante desse diagnóstico o método prescreve a utilização de um Vetor Descritivo do Problema (VDP) com objetivo de expressar os fatos que revelam a existência de um problema e os sintomas que o manifestam, na perspectiva dos atores declarantes. Apresentar o problema através de um vetor descritivo e de descritores complementares tem a intenção de neutralizar a interpretação do mesmo, bem como favorecer sua precisão e monitoramento (BERNARDINO et al., 2006; CORREA et al. 2007).

Aplicando esse conceito, o VDP se apresenta como se mostra no Quadro 2 onde também nesse momento foram identificadas as consequências do problema.

Quadro 2 - VDP, descritores e consequências.

\begin{tabular}{|c|c|}
\hline VDP & Consequências \\
\hline d1: baixa atuação em pesquisa & $\begin{array}{l}\text { Risco de diminuiçãa do desempenho } \\
\text { acadêmico nos avaliadores externos; }\end{array}$ \\
\hline $\begin{array}{l}\text { d2: desequilíbrio de atuação de grupos de } \\
\text { alunos (passividade }- \text { excesso de } \\
\text { atividade) }\end{array}$ & \multirow{4}{*}{$\begin{array}{l}\text { Egresso despreparado para o mercado de } \\
\text { trabalho; } \\
\text { Desprestígio do Curso (Profissão); } \\
\text { Queda na reputação institucional. }\end{array}$} \\
\hline $\begin{array}{l}\text { d3: formação básica do } \begin{array}{l}\text { estudante } \\
\text { deficitária } \\
\text { interpretação, oralidade) }\end{array} \\
\begin{array}{l}\text { ortografia, } \\
\text { (grama, }\end{array}\end{array}$ & \\
\hline $\begin{array}{l}\text { d4: atribuições laborais concomitantes ao } \\
\text { ensino }\end{array}$ & \\
\hline $\begin{array}{l}\text { d5: pouco comprometimento com as } \\
\text { atribuições de ensino (rendimento abaixo } \\
\text { do esperado) }\end{array}$ & \\
\hline
\end{tabular}

Fonte: Resultados da Pesquisa

Observa-se a partir da análise do quadro que os descritores formulados expõem a multisetorialidade do VDP. A baixa atuação em pesquisa assim como o desequilíbrio de atuação de grupo de alunos que estão intimamente ligados à atuação do corpo docente e dos coordenadores. Além disso, os descritores demonstram a diversidade de origens para os problemas, que incluem motivos socioeconômicos relativos à vida particular do aluno, assim como a formação básica deficitária que prejudica o aprendizado e inserção deste aluno no mercado de trabalho. Por fim, o pouco comprometimento do aluno que corrobora com os déficits de aprendizado, provocando o despreparo desse egresso para o mercado de trabalho e prejudicando a reputação da Instituição e desprestígio do curso.

\section{Identificação dos nós críticos}


Com base nos problemas declarados buscou-se, ainda no momento explicativo, identificar os nós críticos que representam as causas sobre as quais os atores têm condições de atuar com eficácia e que possuem direta relação no VDP.

Quadro 3 - Seleção dos nós críticos

\begin{tabular}{|c|c|c|}
\hline Nós Críticos & Ator que Controla & Recurso que controla \\
\hline $\begin{array}{lcr}\text { N1 O } & \text { aluno ingressa } & \text { no } \\
\text { ensino superior sem } & \text { ter } \\
\text { base } & \text { gramatical } & \text { e } \\
\text { interpretativa; } & \end{array}$ & Coordenadores e Docentes & $\begin{array}{l}\text { Capacidade } \\
\text { organizativa } \\
\text { informação. }\end{array}$ \\
\hline $\begin{array}{l}\text { N2 Os professores relatam } \\
\text { que a carga horária } \\
\text { excessiva não permite o } \\
\text { acompanhamento } \\
\text { individualizado do aluno; }\end{array}$ & Coordenadores & $\begin{array}{l}\text { Capacidade política } \\
\text { organizativa. }\end{array}$ \\
\hline $\begin{array}{l}\text { N3 O corpo docente atua } \\
\text { de maneira protecionista } \\
\text { minimizando } \\
\text { responsabilidade do aluno } \\
\text { frente ao processo de } \\
\text { aprendizagem. }\end{array}$ & Coordenadores e Docentes & $\begin{array}{l}\text { Capacidade } \\
\text { organizativa } \\
\text { informação }\end{array}$ \\
\hline $\begin{array}{l}\text { N4 O método avaliativo } \\
\text { não provoca no aluno o } \\
\text { esforço e } \\
\text { necessários para adquirir } \\
\text { conhecimento. }\end{array}$ & Coordenadores e Docentes & $\begin{array}{l}\text { Capacidade } \\
\text { organizativa } \\
\text { informação }\end{array}$ \\
\hline $\begin{array}{l}\text { N5 O curso e a atuação do } \\
\text { profissional não são } \\
\text { devidamente esclarecidos } \\
\text { para a sociedade e para o } \\
\text { corpo discente. }\end{array}$ & Coordenadores e Docentes & $\begin{array}{l}\text { Capacidade } \\
\text { organizativa } \\
\text { informação }\end{array}$ \\
\hline
\end{tabular}

Fonte: Resultados da pesquisa

Em se tratando da atuação do discente frente às demandas acadêmicas, os atores identificaram em maior e menor grau a condição de controle das mesmas, e a partir da análise dos relatos sintetizou-se o momento explicativo no Quadro 4 onde se apresenta o Fluxograma Situacional ou Árvore Explicativa do Problema (DE TONI, 2008). 
Ensino, Saúde e Ambiente - V10 (1), pp. 104-122, Abril. 2017

Quadro 4. Fluxograma Situacional PES - Árvore Explicativa do Problema

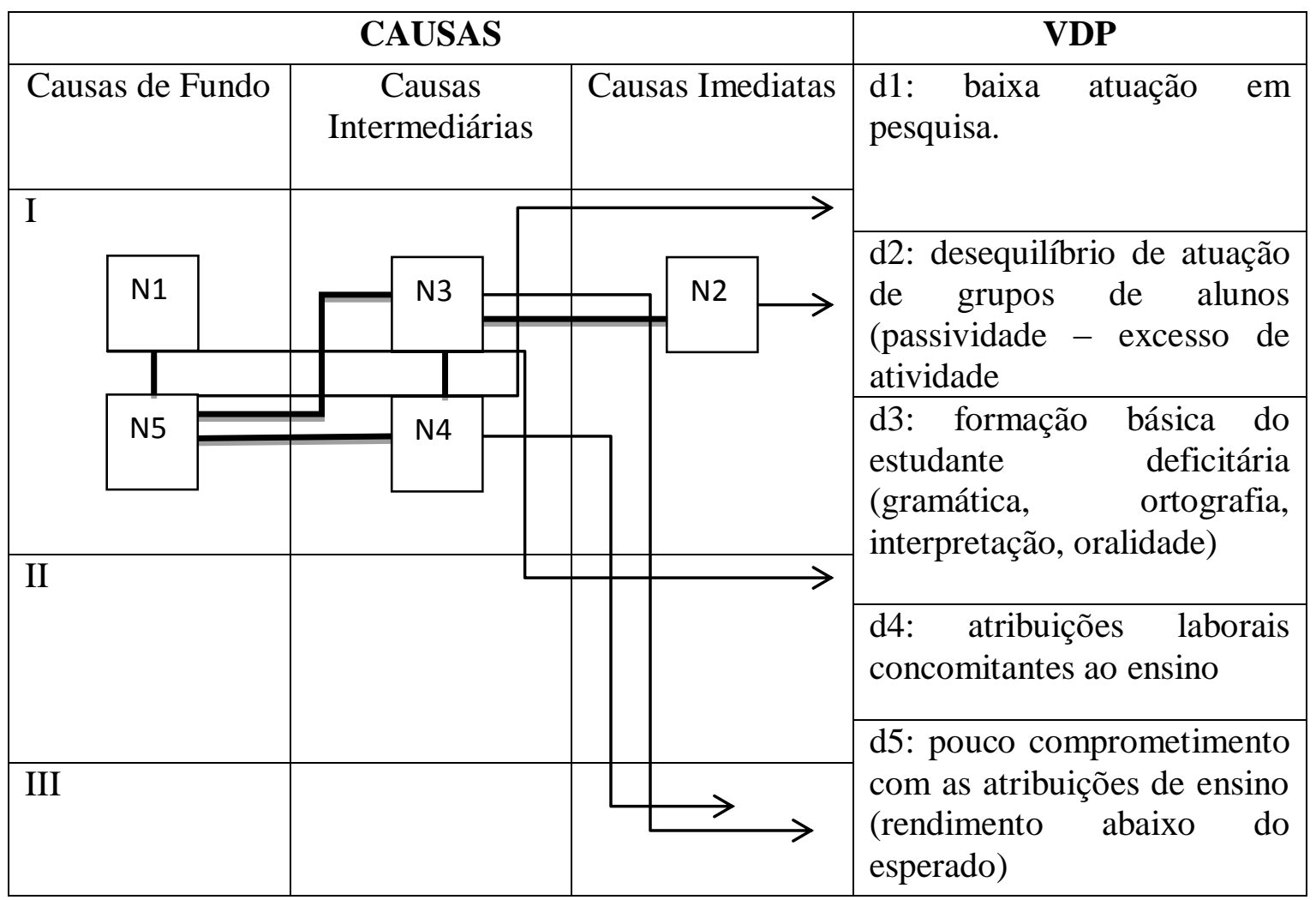

ZONAS DE GOVERNABILIDADE:

I - Sob controle do Planejador

II - Fora do controle do Planejador

III - Fora do jogo

\begin{tabular}{|l|}
\hline \multicolumn{1}{|c|}{ Consequências } \\
\hline $\begin{array}{l}\text { Risco de diminuição do } \\
\text { desempenho acadêmico nos } \\
\text { avaliadores externos; }\end{array}$ \\
Egresso despreparado para o \\
mercado de trabalho; \\
Desprestígio do Curso \\
(Profissão); \\
Queda na reputação \\
institucional.
\end{tabular}


A partir da demonstração da Árvore explicativa do problema, deu-se inicio ao momento normativo, buscando definir os cenários futuros ideais e as ações dos atores na dissolução dos nós críticos.

\section{Concepção de um plano de ação}

$\mathrm{Na}$ etapa seguinte, nomeado momento normativo, apontou-se medidas a serem adotadas pelos atores no sentido de dissolução dos nós críticos, considerando a zona de governabilidade de cada ator e ainda projetando o impacto no VDP.

O resultado se apresenta no Quadro 5 a seguir.

Quadro 5 - Plano de ação para o problema de atuação deficiente do corpo discente.

\begin{tabular}{|c|c|c|c|}
\hline $\begin{array}{c}\text { Nós } \\
\text { Críticos }\end{array}$ & Ações & Responsáveis & $\begin{array}{c}\text { Impacto } \\
\text { VDP }\end{array}$ \\
\hline \multirow[t]{2}{*}{ N1 } & $\begin{array}{l}\text { A1 Oferta de cursos de curta duração } \\
\text { contemplando assuntos do núcleo básico } \\
\text { como gramática e ortografia; }\end{array}$ & $\begin{array}{l}\text { Coordenadores e } \\
\text { Docentes }\end{array}$ & $\begin{array}{l}\text { Médio } \\
\text { Impacto }\end{array}$ \\
\hline & A2 Formação de grupos de leitura; & $\begin{array}{l}\text { Coordenadores e } \\
\text { Docentes }\end{array}$ & $\begin{array}{l}\text { Médio } \\
\text { Impacto }\end{array}$ \\
\hline N2 & $\begin{array}{l}\text { A3 Reformulação do plano de trabalho dos } \\
\text { docentes com reserva de carga horária } \\
\text { exclusiva para atendimento individual do } \\
\text { aluno. }\end{array}$ & Coordenadores & Alto Impacto \\
\hline \multirow[t]{3}{*}{$\mathbf{N 3}$} & $\begin{array}{l}\text { A4 Elaboração de cartilha explicitando as } \\
\text { atribuições relativas à profissão docente tais } \\
\text { como neutralidade e exigências de resultado } \\
\text { coerente com a ementa das disciplinas; }\end{array}$ & $\begin{array}{l}\text { Coordenadores e } \\
\text { Docentes }\end{array}$ & $\begin{array}{l}\text { Médio } \\
\text { Impacto }\end{array}$ \\
\hline & $\begin{array}{l}\text { A5 Aplicação por parte do docente de uma } \\
\text { postura exigente e coerente com as } \\
\text { atribuições profissionais, se preciso, } \\
\text { tornando o fracasso mais natural; }\end{array}$ & Docentes & Alto Impacto \\
\hline & $\begin{array}{l}\text { A6 Promoção de encontros bimestrais para } \\
\text { compartilhamento de experiências e } \\
\text { atualização de planos de trabalho. }\end{array}$ & $\begin{array}{l}\text { Coordenadores e } \\
\text { Docentes }\end{array}$ & Alto Impacto \\
\hline N4 & $\begin{array}{l}\text { A7 Implementação de metodologia de } \\
\text { avaliação visando um maior nível de } \\
\text { exigência, e que coloque o aluno ativamente } \\
\text { na busca pela aprendizagem /aprovação. }\end{array}$ & $\begin{array}{l}\text { Coordenadores e } \\
\text { Docentes }\end{array}$ & Alto Impacto \\
\hline N5 & $\begin{array}{l}\text { A8 Promoção interna e externa de eventos } \\
\text { para difundir a importância do profissional e } \\
\text { da instituição de ensino para a sociedade } \\
\text { bem como para possibilitar o } \\
\text { reconhecimento de outras práticas. }\end{array}$ & $\begin{array}{l}\text { Coordenadores e } \\
\text { Docentes }\end{array}$ & Baixo Impacto \\
\hline
\end{tabular}

Fonte: Resultados da pesquisa

As ações visam conduzir a resultados que sejam monitoráveis e que serão objeto de controle dos atores. Os atores demonstraram interesse em ajustar as práticas e nessa 
etapa dialogaram sistematicamente sobre experiências pessoais, julgando erros e acertos adotados que conduzem ou minimizam o problema.

De maneira geral preocupam-se com uma mudança na cultura do curso, no incentivo à adequação do perfil do estudante e alinhamento da imagem que eles possuem do fazer psicológico com a imagem que os estudantes parecem perceber. Especificamente na experiência relatada nesse trabalho, esse momento constituiu-se como o de maior fertilidade e projeção de melhorias para o enfrentamento do problema.

A partir daí passou-se para o momento estratégico que intenciona a descoberta da viabilidade de execução do Plano de Ação.

\section{Análise estratégica da execução do Plano de Ação}

Passou-se em seguida para o momento estratégico, quando se reflete a viabilidade do Plano de Ação. Nessa etapa são mapeados os atores que tendem a cooperar e aqueles que se opõem ao projeto, as variáveis do jogo social, político, econômico que potencializam ou sabotam sua execução e os recursos essenciais para sua conclusão (BIRCHAL; BERMEJO; ZAMBALDE, 2012).

Partindo de cada ação estratégica o estudo reflexivo das possibilidades e desafios de implementações foi registrado como se explicita no Quadro 6. Nele se estruturou a ação descrita em subações que alcancem as operações; a demonstração da viabilidade de decisão, execução e manutenção de cada uma delas; o que existe de recursos para ocorrerem e quais são aqueles recursos necessários, e ainda em síntese a atividade estratégica. 
Quadro 6 - Mapa do momento estratégico

\begin{tabular}{|c|c|c|c|c|c|c|}
\hline \multirow[t]{2}{*}{$\begin{array}{l}\text { Ações Específicas para realização das ações } \\
\text { gerais }(\mathbf{A 1}, \mathbf{A 2} \ldots \mathbf{A 8}) \text {. }\end{array}$} & \multicolumn{3}{|c|}{$\begin{array}{l}\text { Viabilidade } \\
\text { (Poder) }\end{array}$} & \multicolumn{2}{|c|}{ Factibilidade } & \multirow[t]{2}{*}{$\begin{array}{l}\text { Atividade } \\
\text { Estratégica }\end{array}$} \\
\hline & Decidir & Executar & Manter & $\begin{array}{c}\text { Recursos } \\
\text { Existentes }\end{array}$ & $\begin{array}{c}\text { Recursos } \\
\text { Necessários }\end{array}$ & \\
\hline $\begin{array}{l}\text { A1 } \\
\text { Contato com ator-chave para condução de curso; } \\
\text { Divulgação institucional para estudantes }\end{array}$ & $\begin{array}{l}\text { SIM } \\
\text { SIM }\end{array}$ & $\begin{array}{l}\text { NÃO } \\
\text { SIM }\end{array}$ & $\begin{array}{l}\text { NÃO } \\
\text { SIM }\end{array}$ & $\begin{array}{l}\text { Salas e horários } \\
\text { Equipe }\end{array}$ & $\begin{array}{l}\text { Ator externo } \\
\text { Material de divulgação }\end{array}$ & \multirow{2}{*}{$\begin{array}{l}\text { Articulação } \\
\text { logística e de } \\
\text { busca de } \\
\text { parcerias } \\
\text { institucionais } \\
\text { ou } \\
\text { contratações }\end{array}$} \\
\hline $\begin{array}{l}\text { A2 } \\
\text { Contato com ator-chave para condução de curso; } \\
\text { Divulgação institucional para estudantes }\end{array}$ & $\begin{array}{l}\text { SIM } \\
\text { SIM }\end{array}$ & $\begin{array}{l}\text { NÃO } \\
\text { SIM }\end{array}$ & $\begin{array}{l}\text { NÃO } \\
\text { SIM }\end{array}$ & $\begin{array}{l}\text { Salas e horários } \\
\text { Equipe Colegiado }\end{array}$ & $\begin{array}{l}\text { Ator externo } \\
\text { Material de divulgação }\end{array}$ & \\
\hline $\begin{array}{l}\text { A3 } \\
\text { Elaboração de redistribuição de horas docentes; } \\
\text { Promoção de horário de atendimento ao discente } \\
\text { por disciplina }\end{array}$ & SIM & NÃO & NÃO & Equipe Colegiado & $\begin{array}{l}\text { Alteração regimento } \\
\text { Sala individual de } \\
\text { trabalho }\end{array}$ & $\begin{array}{l}\text { Alterar } \\
\text { normativas } \\
\text { institucionais. }\end{array}$ \\
\hline $\begin{array}{l}\text { A4 } \\
\text { Redação de material teórico-técnico } \\
\text { Solicitação institucional para confecção }\end{array}$ & SIM & SIM & SIM & $\begin{array}{l}\text { Competência técnica } \\
\text { Equipe instituição }\end{array}$ & - & $\begin{array}{l}\text { Articulação } \\
\text { com } \\
\text { responsáveis } \\
\text { pelas } \\
\text { produções }\end{array}$ \\
\hline
\end{tabular}


Ensino, Saúde e Ambiente - V10 (1), pp. 104-122, Abril. 2017

\begin{tabular}{|c|c|c|c|c|c|c|}
\hline \multirow[t]{2}{*}{$\begin{array}{l}\text { Ações Específicas para realização das ações } \\
\text { gerais }(\mathbf{A 1}, \mathbf{A 2} \ldots \mathbf{A 8}) \text {. }\end{array}$} & \multicolumn{3}{|c|}{$\begin{array}{l}\text { Viabilidade } \\
\text { (Poder) }\end{array}$} & \multicolumn{2}{|c|}{ Factibilidade } & \multirow[t]{2}{*}{$\begin{array}{l}\text { Atividade } \\
\text { Estratégica }\end{array}$} \\
\hline & Decidir & Executar & Manter & $\begin{array}{c}\text { Recursos } \\
\text { Existentes }\end{array}$ & $\begin{array}{c}\text { Recursos } \\
\text { Necessários }\end{array}$ & \\
\hline Distribuição de material & $\begin{array}{l}\text { SIM } \\
\text { SIM }\end{array}$ & $\begin{array}{l}\text { NÃO } \\
\text { SIM }\end{array}$ & $\begin{array}{l}\text { SIM } \\
\text { SIM }\end{array}$ & $\begin{array}{l}\text { Equipe } \\
\text { Colegiado }\end{array}$ & $\begin{array}{l}\text { Recursos } \\
\text { Material de divulgação }\end{array}$ & $\begin{array}{l}\text { gráficas do } \\
\text { Centro } \\
\text { Universitário }\end{array}$ \\
\hline $\begin{array}{l}\text { A5 } \\
\text { Conduta do Colegiado }\end{array}$ & SIM & SIM & SIM & Equipe Colegiado & - & \\
\hline $\begin{array}{l}\text { A6 } \\
\text { Agendamento de reuniões bimestrais; } \\
\text { Comparecimento em reunião; } \\
\text { Elaboração e atualização de Plano de } \\
\text { Trabalho/Ensino }\end{array}$ & $\begin{array}{l}\text { SIM } \\
\text { SIM } \\
\text { SIM }\end{array}$ & $\begin{array}{l}\text { SIM } \\
\text { SIM } \\
\text { SIM }\end{array}$ & $\begin{array}{l}\text { SIM } \\
\text { SIM }\end{array}$ & $\begin{array}{l}\text { Sala para reunião } \\
\text { Equipe Colegiado } \\
\text { Equipe Colegiado }\end{array}$ & - & $\begin{array}{l}\text { Organizar } \\
\text { trabalho } \\
\text { sistemático de } \\
\text { controle por } \\
\text { parte da } \\
\text { gestão; } \\
\text { Fixar agenda } \\
\text { de trabalhos: }\end{array}$ \\
\hline $\begin{array}{l}\text { A7 } \\
\text { Elaboração de provas com adequado nível de } \\
\text { exigência; } \\
\text { Nivelamento de padrão de exigência entre } \\
\text { docentes; } \\
\text { Envio de provas para análise da gestão antes de } \\
\text { aplicação; } \\
\text { Constante atualização de método de avaliação; }\end{array}$ & SIM & SIM & SIM & $\begin{array}{l}\text { Equipe Colegiado } \\
\text { Equipe Gestora } \\
\text { Equipe } \\
\text { Colegiado } \\
\text { Equipe Colegiado }\end{array}$ & $\begin{array}{l}\text { Envio de provas para } \\
\text { análise. } \\
\text { - }\end{array}$ & $\begin{array}{l}\text { Promover } \\
\text { aproximações } \\
\text { constantes do } \\
\text { colegiado } \\
\text { como um todo } \\
\text { para fomentar } \\
\text { uniformidade } \\
\text { criativa na } \\
\text { conduta } \\
\text { docente. }\end{array}$ \\
\hline
\end{tabular}


Ensino, Saúde e Ambiente - V10 (1), pp. 104-122, Abril. 2017

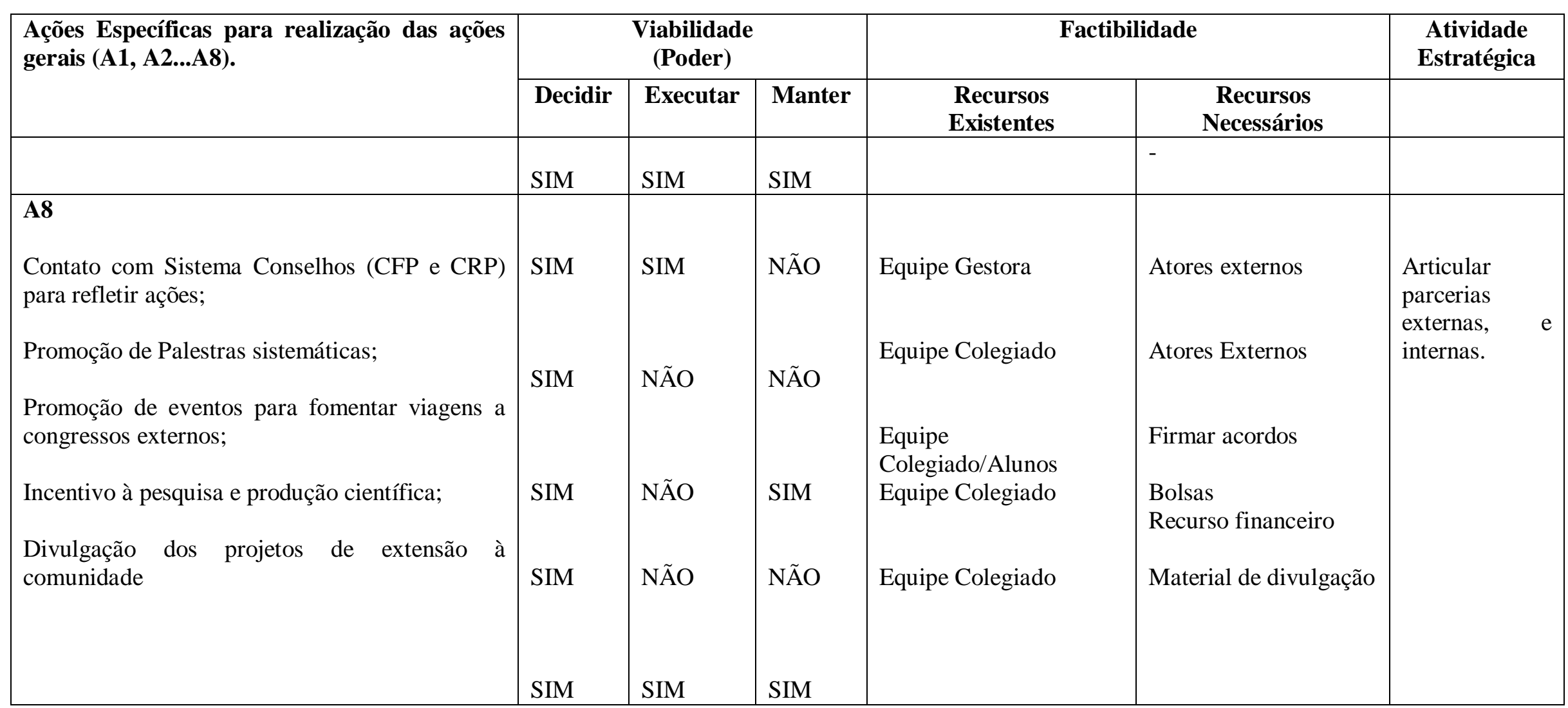

Fonte: Resultados da Pesquisa 
Vale salientar que a metodologia PES é continuada e deve ser assumida pelos próprios atores sociais participantes. Nesse caso específico a atuação dos coordenadores e professores no âmbito de suas competências é que se configura fator primordial na execução, controle e sucesso desse planejamento aqui disposto.

$\mathrm{Na}$ condução dessa residência reforçamos a aplicabilidade do PES como instrumento de planejamento. Foram executadas as etapas explicativa, normativa e estratégica, porém destaca-se a impossibilidade de executar nessa pesquisa a relevante adequação periódica das estratégias, ação que compete aos próprios atores sociais incluídos em todo o processo.

Este trabalho alcançou a etapa estratégica, ciente do passo seguinte que seria a tático-operacional, mas que por essa pesquisa não foi contemplada por conta da determinação de prazo para conclusão do trabalho que ora se apresenta.

\section{CONSIDERAÇÕES FINAIS}

A atividade de planejamento, além de mostrar-se bastante eficiente na definição de metas para curto, médio e longo prazo, apresenta-se como uma importante ferramenta na investigação do cenário e dos atores envolvidos no jogo social. O PES, em sua metodologia exploratória, atua intrinsicamente na mensuração e exposição dos fatores externos e internos e, mais importante, na demonstração dos problemas que comprometem o ensino-aprendizagem, os índices de eficiência e eficácia, a reputação e a permanência da Instituição no cenário em que está inserida.

Ficou notório que a enumeração dos fatores limitantes se apresenta de maneiras diferentes, a partir da perspectiva do ator social e de suas contribuições e atribuições para o surgimento e resolução de determinado problema. Neste sentido, a metodologia utilizada foi bastante eficiente para sintetizar a visão social dos participantes no que diz respeito aos problemas enfrentados no curso de Psicologia desta instituição, de maneira que esse diagnóstico fosse fidedigno e participativo. Para isso ressalta-se a importância da promoção de diversas reuniões com objetivos diferentes, onde em algumas se busca a interação dos atores e em outras se busca proporcionar a privacidade de determinado grupo a fim de que este exponha com mais liberdade a sua concepção sobre a sua própria atuação e a atuação dos demais envolvidos.

Outro fator importante disposto no método foi a definição da zona de governabilidade que se mostrou bastante útil na delimitação do alcance dos problemas e na definição dos nós e das ações que podem ser praticadas pelos atores, nesse momento 
é possível visualizar quais problemas são sanáveis e quais problemas extrapolam as competências e atribuições de gestores, coordenadores e professores desta Instituição.

\section{REFERÊNCIAS BIBLIOGRÁFICAS}

ARTMANN, E., AZEVEDO, C.S. e SÁ, M.C. Possibilidades de aplicação do enfoque estratégico de planejamento no nível local de saúde: análise comparada de duas experiências. Rio de Janeiro: Cadernos de Saúde Pública, 13(4):723-740, out-dez, 1997.

BERNARDINO, E.; OLIVEIRA, E.; CIAMPONE, M. H. T. Preparando enfermeiros para o SUS: o desafio das escolas formadoras. Revista Brasileira de Enfermagem, Brasília, v. 59, n. 1, p. 36-40, Feb. 2006.

BIRCHAL, F. F. S.; ZAMBALDE, A. L.; BERMEJO, P. H. S. Planejamento estratégico situacional aplicado à segurança pública em Lavras (MG). Revista de Administração Pública, Rio de Janeiro, v. 46, n. 2, p. 523-545, Apr. 2012.

DAROSI, G. C. M. Análise da Produção Científica sobre Planejamento Estratégico Situacional. Revista Brasileira de Administração Científica, Aquidabã, v.5, n.1, Jan, Fev, Mar, Abr, Mai, Jun 2014.

DE TONI, J., SALERNO, G. e BERTINI, L. Uma abordagem estratégica no planejamento de grupos: o Método Altadir de Planejamento Popular - MAPP. In JACQUES, MGC., et al. org. Relações sociais e ética [online]. Rio de Janeiro: Centro Edelstein de Pesquisas Sociais, 2008. p. 140- 150.

GONÇALVES, L. R. G., CINTRA, G. B., TEIDER, B. H., GALLO, J. B., E PANDOLFELLI, V. C. Aplicação da ferramenta SWOT para avaliação das técnicas de dano ao choque térmico em materiais refratários. Cerâmica, São Paulo, v. 56, n. 340, p. 320-324, Dec. 2010

GONZALEZ, M. M. L. Planejamento estratégico em saúde com base em determinantes: o caso do município de Campo Bom (RS). Uma proposta metodológica para a gestão descentralizada. Ciência e Saúde Coletiva, Rio de Janeiro, v. 14, supl. 1, p. 15871597, out. 2009.

HUERTAS, F. O método PES: entrevista com Matus (em português). Tradução Giselda Barroso Sauveur. 1 ${ }^{\text {a }}$ ed. São Paulo: Fundap, 1996. 139 p.

MATUS, C. Política, planejamento e governo. Brasília: Ipea, 1993. . Adeus, senhor Presidente: governantes governados. São Paulo: Edições Fundap, 1996.

MIZAEL, G. A.; BOAS, A. A. V.; PEREIRA, J. R. Análise do Plano de

Desenvolvimento Institucional das universidades federais do Consórcio Sul-Sudeste de Minas Gerais. Revista de Administração Pública, Rio de Janeiro, v. 47, n. 5, p. 11451164, out. 2013.

PAIM, J. J. Planejamento em saúde para nãoe specialistas. In: CAMPOS G. W.

Tratado de Saúde Coletiva. Rio de Janeiro, Fiocruz, 2006, pag. 15-30.

RIEG, D. L.; ARAUJO FILHO, T. O uso das metodologias "Planejamento Estratégico Situacional" e "Mapeamento Cognitivo" em uma situação concreta: o caso da próreitoria de extensão da UFSCar. Gestão e Produção, São Carlos, v. 9, n. 2, p. 163179, ago. 2002. 